\title{
Filosofia da tecnologia e educação: conservação ou crítica inovadora da modernidade?
}

\author{
Geraldo Antônio da Rosa \\ Amarildo Luiz Trevisan
}

Resumo: O campo dos estudos sobre ciência e tecnologia e seus benefícios na vida das populações está sendo questionado de maneira veemente nos últimos tempos. A justificativa de que o desenvolvimento da ciência e da tecnologia avança de maneira inexorável e neutra caiu por terra, frente às inúmeras confrontações e limites a que ficou exposta essa racionalidade. São muitos testemunhos e mesmo movimentos teóricos que questionam essa crença atualmente. Nesse texto, pretende-se delimitar alguns marcos teórico-conceituais nos quais se desenvolvem tais propostas do ponto de vista de sua relação com a educação. Para isso, parte-se da discussão, proposta por Marilena Chauí, sobre o modo como se constitui a racionalidade moderna e sua forma de apropriação pelas populações através da ideologia do cientificismo. A seguir, a crítica a essa racionalidade é avaliada segundo os preceitos da Escola de Frankfurt, especialmente na visão de Marcuse e Feenberg. Por último, procura-se apresentar alguns fundamentos dos estudos do movimento Ciência, Tecnologia e Sociedade $(C T \& S)$ sobre essas questões, derivando reflexões para o campo da educação. Trata-se de avançar a discussão de suas origens, conforme exposto na filosofia da tecnologia, de Heidegger, a qual acredita ser destino da humanidade viver sob a égide da técnica, em busca de uma outra relação com a realidade, mais em harmonia com a natureza.

Palavras-chave: Filosofia da tecnologia. Sociedade. Educação.

Philosophy of technology and education: Conservation or innovative critique of modernity?

Abstract: The field of studies about science and technology and its benefits in the lives of the people have been vehemently questioned in recent times. The justification that the development of science and technology advances inexorably and neutrally fell apart in front of the numerous confrontations and limits that was exposed this rationality. There are many testimonies and even theoretical movements that challenge this belief today. In this text, there is the intention to define some theoretical and conceptual frameworks in which ones these proposals have been develop in terms of their relation to education. For this, it starts from the discussion, proposed by Marilena Chauí, about how modern rationality is constituted and its form of appropriation by the people through the scientism ideology. Following, the criticism of this rationality is assessed according to the precepts of the Frankfurt School, especially under the view of Marcuse and Feenberg. Finally, it has been trying to present some fundamentals of the Science, Technology and Society studies (ST\& S) on these issues, deriving reflections to the field of education. It comes to advance the discussion of its origins, as discussed in Heidegger's philosophy of technology, which it is believed to be the fate of humanity, living under the aegis of the technique, in search of a different relationship with reality, more in harmony with nature.

Key words: Philosophy of technology. Society. Education. 
Mas, quando o século XX avançou das guerras mundiais para os campos de concentração e para catástrofes ambientais, ficou mais difícil ignorar a estranha falta de sentido da modernidade, porque estamos sem saber onde estamos indo e por que a filosofia da tecnologia emergiu, em nossos tempos, como uma crítica dessa modernidade (FEENBERG, 2010, p. 44).

\section{Considerações iniciais}

A ciência e a tecnologia são produtos típicos da modernidade por encarnar em sua essência o ideário da busca do novo, ou da novidade constante. No entanto, nos últimos tempos têm-se levantado alguns questionamentos sobre o quanto realmente existe de inovação nos produtos científicos e tecnológicos permanentemente postos à disposição no mercado como "novidades", ou, de outro modo, se essa matriz não tem contribuído para a produção de catástrofes de toda ordem, como as guerras, a degradação ambiental e, mais recentemente, o aquecimento global.

Problemas científicos associados à relação do ser humano com os recursos naturais estão entre os de maior interesse e repercussão social no presente momento. Dentre esses, está a compreensão dos desastres naturais, incluindo sua previsibilidade e seus impactos para a sociedade e o entendimento sobre variabilidade e mudanças climáticas, tanto em termos de diagnóstico como de prognósticos. O aquecimento global é um dos problemas com maior destaque no cenário científico internacional. A pesquisa na área envolve desde o diagnóstico de sua ocorrência até a projeção de seus impactos em diferentes cenários futuros do nosso planeta. Algumas das mais importantes implicações das mudanças climáticas às atividades humanas estão associadas a questões agrícolas, de segurança alimentar e à necessidade de geração de energias renováveis. Porém, a partir de documentos oficiais brasileiros que apontam atualmente a preocupação com o desenvolvimento de um sistema de prevenção às catástrofes naturais ${ }^{1}$, perguntamos: $\mathrm{O}$ que poderia auxiliar na prevenção a eventos traumáticos provocados pelo descaso humano, especialmente em relação à matriz de desenvolvimento científico e tecnológico adotada?

1 Preocupação prevista no documento Estratégia Nacional de Ciência, Tecnologia e Inovação 2012 2015. Balanço das Atividades Estruturantes 2011, expedido pelo governo federal através do Ministério de Ciência Tecnologia e Inovação (BRASIL. MCTI, 2012). O documento informa que "o MCTI está desenvolvendo, em articulação com outras instituições federais, estaduais, municipais, órgãos de defesa civil e as Forças Armadas, um Sistema Nacional de Monitoramento e Alertas de Desastres Naturais. O resultado desse esforço aumentará a capacidade da sociedade brasileira para fazer frente às catástrofes naturais, com redução de vítimas e de prejuízos sociais e econômicos decorrentes, contribuindo para diminuição da pobreza e aumento da qualidade de vida" (2012, p. 106). 
A necessidade de propor reflexões sobre os riscos catastróficos de viver sob a égide dos modos hegemônicos de produzir ciência e tecnologia tem sido feita a partir de suas origens, na filosofia da tecnologia de Martin Heidegger, como uma crítica conservadora da tradição, tendo como continuadores dessa crítica, dentre outros, os filósofos Hans-Georg Gadamer e Hannah Arendt. Isso não significa que a conservação seja algo negativo, mas antes tem a ver com a necessidade do não abandono das tradições que nos constitui no tempo presente. Esse é um caminho promissor, pois conduz muitas vezes ao desocultamento da gênese dos problemas que ora enfrentamos.

Neste texto, porém, pretendemos dar seguimento a essa crítica a partir de um dos preceitos modernos mais importantes - a inovação - repensando alternativas aos modos hegemônicos de produção de ciência e tecnologia. Cremos ser necessário avançar na crítica, pois o caminho inverso, ou seja, a volta das novas gerações ao cultivo das tradições - sem a sua renovação constante - parece uma batalha perdida. O objetivo do artigo não é estabelecer o confronto das diferentes abordagens sobre o tema, mas mostrar o seguimento dessa problemática para então estabelecer algumas reflexões, especialmente do ponto de vista dos Estudos Sociais de Ciência e Tecnologia - ESCT. Esse campo de pesquisa investiga a relação Ciência, Tecnologia e Sociedade, especialmente a defesa da dimensão social dos conceitos de tecnologia e inovação, derivando reflexões para o campo da educação. Pretendemos por em pauta algumas intuições sobre o problema fazendo uma retomada das argumentações desenvolvidas pelos autores de referência, com o intuito de mostrar a sua relevância para estudantes e educadores. Não é intento fazer uma exegese exaustiva dos autores e muito menos um questionamento de suas posições; antes disso nos compete justificar o porquê se torna indispensável hoje, no contexto da educação, o questionamento das racionalidades matriciais que pautam, em largo sentido, as pesquisas sobre ciência e tecnologia no Brasil e suas formas de apropriação pelas populações.

Posta a discussão da tecnologia e da ciência no panorama mais amplo de crise do projeto da modernidade, é preciso debater a sua importância na emancipação dos povos, na tentativa de ir além da sua compreensão na relação fechada de neutralidade, debatendo a inclusão de mais um termo a essa discussão: a relação entre ciência e tecnologia com a sociedade. Nesse contexto, faz-se mister discutir algumas questões: Será que a sociedade participa dos processos decisórios a respeito dos rumos das políticas científicas e tecnológicas numa perspectiva de democratização? É possível o entendimento do complexo tecnocientífico não como um sistema de dominação, mas como aliado de uma biopolítica eman- 
cipatória? Que dinâmica pode ser adotada contemporaneamente para vincular o avanço social ao desenvolvimento científico e tecnológico? Que modelo de acesso à ciência e tecnologia está sendo proporcionado às crianças e jovens na escola hoje? Como essas questões estão sendo tratadas nos diferentes contextos educacionais? Em que medida e de que modo essas discussões podem ser operacionalizadas nas instituições de ensino?

Esses questionamentos serão debatidos neste trabalho a partir da exploração dos potenciais da filosofia da tecnologia, que emerge das suas origens heideggerianas em busca de um cenário de maior equidade. Para isso, problematizaremos inicialmente algumas controvérsias científicas e tecnológicas segundo o diagnóstico proposto por Marilena Chauí. A seguir, trataremos da crítica à racionalidade tecnológica de acordo com os preceitos da Escola de Frankfurt, especialmente na apropriação de Andrew Feenberg, levando em consideração a apreciação que ele faz do debate ensaiado a esse respeito entre Habermas e Marcuse. Por último, procuraremos mostrar a posição dos estudos do movimento Ciência, Tecnologia e Sociedade (CT\&S) sobre essas questões, salientando a necessidade de uma interlocução mais aguda a respeito da apropriação dos meios tecnológicos pela sociedade, tornando ainda mais indispensável contemporaneamente o diálogo sobre os seus efeitos. Nesse ponto o pensamento freiriano também se torna importante, no sentido de incentivar a participação a partir da problematização junto aos diferentes segmentos sociais, adotando-se uma metodologia dialógica que levante elementos para a construção de uma agenda com efetiva participação da sociedade, em termos de ciência e tecnologia.

\section{Controvérsias científicas e tecnológicas}

Para Marilena Chauí (1997), por muitos anos a humanidade vivenciou um ideal científico calcado na ideia de demonstração e prova, a partir da demarcação do objeto do conhecimento. Sendo assim, a ciência que se constitui a partir do início da idade moderna está baseada nas características de distinção entre sujeito e objeto do conhecimento, na ideia de método, nas operações de análise, síntese e na lei do fenômeno. Outro aspecto a ser destacado nesse processo é a utilização de elementos tecnológicos que podem ser concebidos como a Ciência cristalizada em objetos materiais destinados à dominação e transformação do mundo e não meramente facilitar a relação do homem com o mundo. Quanto à linguagem científica, ressalta-se que a mesma transcende o simbolismo da linguagem cotidiana, construindo uma linguagem própria, com símbolos unívocos e denotativos de significado único e universal. 
A partir do antropocentrismo renascentista, o homem é colocado diante de um dilema entre o conhecimento desinteressado da ciência e o utilitarismo que centra sua concepção de ciência no quantitativo de aplicações práticas. Essas duas concepções apontam para discussões acerca de uma ciência pura e uma ciência aplicada, cujos limites são superados a partir de concepções da filosofia da ciência na contemporaneidade. Evidencia-se que em nível de senso comum existe uma dificuldade no discernimento entre ciência pura e ciência aplicada, entre teoria e prática, entre verdade e utilidade, restringindo as ciências ao resultado de suas aplicações. O senso comum ignora as transformações da ciência e da técnica, conhecendo apenas seus resultados imediatos, ou seja, identifica o conhecimento científico pelos seus efeitos tecnológicos. Essa situação nos coloca diante da falta de percepção do essencial, segundo Chaui (1997), de que as ciências passaram a fazer parte das forças produtivas da sociedade e trouxeram mudanças sociais de grande porte na divisão e controle social do trabalho, na produção e distribuição dos objetos e na forma de consumi-los.

Uma questão crucial a ser refletida nesse contexto é a da falta de percepção dos mecanismos de poder que envolvem a produção científica, ou seja, de que as pesquisas científicas são financiadas por empresas e governos, demandando grandes somas de recursos que retornam, graças aos resultados obtidos, na forma de lucro e poder para os agentes financiadores. Enfim, pouco se percebe o poderio econômico das ciências e por isso nossa luta se restringe ao acesso e consumo dos objetos tecnológicos, e não priorizamos uma luta pelos direitos de decidir seu modo de inserção na vida econômica e política de uma sociedade. Em nosso cotidiano frequentemente vamos a uma loja de informática para aquisição de celulares, tablets, notebooks, smartphones. Nossa vida é marcada por escolhas para solucionar problemas, o que significa aquisição de artefatos tecnológicos para a solução desses problemas. A partir de tais pressupostos, podemos concluir que, ao longo da história da humanidade, da tecnologia do osso à nanotecnologia, graças ao desenvolvimento da tecnociência, o ser humano constrói artefatos tecnológicos que lhe permitem operar no ambiente. Porém, os artefatos tecnológicos não se reduzem à tecnologia, uma vez que ela se encontra associada ao processo de construção dos artefatos, bem como ao seu processo de manipulação. A partir dessa concepção nossos problemas sociais e culturais não serão solucionados com a simples utilização de artefatos, o que pode levar cada vez mais à criação da montanha de lixo, mas levando em conta uma discussão sobre a forma ou o seu processo de construção. Por isso, fruto da dissociação entre resultados tecnológicos e processos decisórios, ainda se acredita hoje, no Brasil, em políticas educacionais que profissionali- 
zam os jovens no segundo grau - portanto, antes que tenham podido ter acesso às ciências propriamente ditas - e que destinam poucos recursos públicos às áreas de pesquisa nas universidade - portanto, mantendo os cientistas na mera condição de reprodutores de ciências produzidas em outros países e sociedades (CHAUI, 1997, p. 285).

Frente aos enigmas e obstáculos epistemológicos enfrentados pelos cientistas, por um lado o senso comum coloca-se diante da ideologia de uma ciência que no processo de evolução do conhecimento abarca uma aplicação total da realidade. Por outro, numa perspectiva de mitologia da ciência, lhe são atribuídos poderes ilimitados, dando-lhe o lugar outrora ocupado pelas religiões. Essa postura se deve ao cientificismo, ou seja, à fusão entre ciência e técnica, e à ilusão da neutralidade científica, que desenvolveu uma falsa crença na racionalidade do progresso. Do mesmo modo se coloca a ideologia da competência, ou seja, os que sabem são considerados competentes e os que não sabem, os incompetentes, e por isso devem executar tarefas que lhes são ordenadas. Ressalta-se que neste mesmo período a sociedade capitalista pautava-se pelos pressupostos de que o progresso social e histórico provinha da competição e concorrência dos indivíduos, seguindo a lei econômica da oferta e da procura.

A proposta de Chaui apresenta os limites em que ocorre, de modo geral, o debate sobre ciência e tecnologia na sociedade capitalista, na medida em que a luta permanece refém da tentativa de consumo dos seus produtos, pouco se preocupando com os mecanismos de poder subjacentes a esses processos. Enquanto ela aposta numa crítica do poder, apelando para a democratização do debate, com o maior envolvimento da população com os processos de produção e manipulação desses mecanismos, Herbert Marcuse e Andrew Feenberg vão depositar suas esperanças na crítica cultural, especialmente conferindo importância à arte e à estética como vetores dessa compreensão.

\section{Marcuse e Feenberg: teoria crítica da tecnologia}

A cisão entre o fazer científico e sua apropriação pela sociedade também foi questionada pelos expoentes da Escola de Frankfurt, que descreveram a racionalidade ocidental como instrumentalização da razão. No princípio, a razão que se contrapunha ao mito acaba virando uma nova mitologia, dando justificativa à ideia de linearidade do progresso puxada pelos avanços científicos e tecnológicos. A razão instrumental - que Adorno e Horkheimer - designaram como a expressão da razão iluminista - e que nasce do gesto de Ulisses frente às sereias na Odisséia, de Homero- se constitui quando o sujeito do conheci- 
mento toma a decisão de que conhecer é dominar a natureza e, a partir daí os seres humanos. Portanto, a ciência vai deixando de ser uma forma de acesso aos conhecimentos de padrões culturais para se tornar um instrumento de dominação, poder, exploração e, consequentemente, de destruição. Esse diagnóstico pessimista faz eco à tese heideggeriana de que a instrumentalização da razão se tornou absoluta e não há como fazer frente a esse problema a partir da própria matriz de ciência e tecnologia adotada.

Andrew Feenberg ${ }^{2}$ procura avançar essa questão ao se basear em Marcuse, principalmente na sua obra póstuma Tecnologia, Guerra e Fascismo (MARCUSE, 1999), para alertar sobre os riscos catastróficos de viver sob a égide dos modos hegemônicos de produzir ciência e tecnologia, principalmente do ponto de vista do determinismo e do instrumentalismo, os quais defendem a neutralidade da ciência e a fé no progresso técnico. Fruto dessa crença, surge uma modernização forçada, preocupada com os seus fins exclusivamente, o que desencadeou sérios riscos para a convivência no planeta, ocasionando catástrofes como as guerras entre os povos e a degradação ambiental.

Por isso se faz necessário atualmente, segundo ele, uma teoria crítica da técnica ou filosofia da tecnologia, para questionar o tipo de racionalidade que contribui para a produção de catástrofes. Nesse sentido, é preciso retirar a filosofia da tecnologia de suas origens heideggerianas e colocá-la no patamar de enfrentamento dos efeitos criados por essa racionalidade. É por isso que, ao prefaciar a obra Andrew Feenberg: racionalização democrática, poder e tecnologia, Renato Dagnino adverte que: "Ela fornece um guia seguro para pesquisadores e fazedores de política que no mundo inteiro buscam uma visão crítica sobre a tecnociência que contribua para evitar as catástrofes sociais, econômicas e ambientais que rondam nossa civilização" (2010, p. 20).

No artigo Marcuse ou Habermas: duas críticas da tecnologia, Feenberg (2010) fala que esses autores estiveram de certa maneira em lados opostos a respeito do tema da tecnologia. Enquanto Habermas faz uma crítica à racionalidade instrumental, mas mantém os seus pressupostos, Marcuse avança para uma concepção mimética ou solidária da tecnologia, sendo capaz de

2 Andrew Feenberg foi aluno de Herbert Marcuse e atualmente é pesquisador em Filosofia da Tecnologia na Escola de Comunicação, Simon Fraser University (Canadá), onde dirige o Laboratório de Tecnologia e Comunicação Aplicada. Entre suas obras estão Heideger and Marcuse: The Catastrophe and Redemption of History pela Editora Routledge, 2005; Between Reason and Experience: Essays in Technology and Modernity pela Editora MIT, 2010; uma coleção coeditada The Essential Marcuse pela Editora Beacon, 2007, e (Re)Inventing the Internet publicado este ano pela Editora Sense. Em língua portuguesa, destacam-se os capítulos 1 e 7 de Transforming Technology e a obra Andrew Feenberg: Racionalização Democrática, Poder e Tecnologia, organizada por Ricardo T. Neder (2010), uma coletânea de artigos de Feenberg publicada pela primeira vez na América Latina. 
transcender o seu espectro restrito de atuação. Influenciado por Max Weber, Habermas concebe os pioneiros da Escola de Frankfurt, especialmente Adorno, Horkheimer, Benjamin e Marcuse, presos a uma visão romântica da natureza. Segundo ele, as suas esperanças secretas de um acordo mimético ou fraternal do homem com a natureza, vista como um outro sujeito, sucumbem frente a uma racionalidade que não conhece outro modo de operar senão o instrumental. Em lugar dessa expectativa, propõe o diagnóstico da relação entre mundo da vida e sistema numa perspectiva colonizadora do segundo sobre o primeiro, resultando na tecnificação do mundo da vida que redunda nas patologias sociais ou patologias da colonização (reificação).

No entanto, essa análise presente em obras como Técnica e ciência enquanto ideologia e Conhecimento e interesse não foi levada adiante, permanecendo um silenciamento na Teoria da Ação Comunicativa sobre a influência sócio-histórica na concepção da tecnologia. As esferas da racionalidade, divididas entre ciência, moralidade e arte adquirem autonomia de execução na modernidade, tornando os seus procedimentos formais e abstratos. A esfera da ciência e da tecnologia só admite uma atitude objetivante, enquanto a esfera prático-moral acolhe a relação intersubjetiva propriamente dita, ficando a esfera da subjetividade, dos sonhos e fantasias por um mundo melhor refém da aura estética. Porém, contaminado por essa crítica, Habermas acaba concebendo a racionalidade instrumental orientada para o êxito (da ciência e tecnologia) como neutra e não-social e restrita ao seu próprio nicho de atuação. Por isso vai apostar no desenvolvimento da racionalidade prático-moral, tendo esta o poder de redirecionar o desenvolvimento da razão, permitindo, pelos acordos comunicativos ou intersubjetivos, a emergência de uma sociedade mais fraterna e solidária.

Marcuse não discorda de que as aspirações por uma sociedade liberada ficaram reféns de uma racionalidade estética, porém acredita que ela serve de fonte de inspiração para pensar outra racionalidade, concebida nos moldes e padrões dos procedimentos tecno-científicos. Enquanto Adorno e Horkheimer, na Dialética do esclarecimento, defendiam que tanto a natureza interna quanto a externa eram destruídas pela racionalidade do progresso, Marcuse acredita no poder da arte para inspirar uma relação não-alienada entre homem e o seu meio de existência. Nesse aspecto, em A ideologia da sociedade industrial: o homem unidimensional, ele se mostra menos influenciado pelo diagnóstico heideggeriano do que os seus colegas da Escola de Frankfurt, que acreditavam ser destino da humanidade viver sob a égide da técnica tal como o capitalismo a apresenta. Para evitar os riscos catastróficos a que a humanidade estaria ex- 
posta, caso seguisse por esse caminho, Feenberg parte de duas fontes básicas de pesquisa, ao afirmar que:

A prática estética oferece um modelo a Marcuse para defender a possibilidade de uma revolução nas forças produtivas e sociais, a partir da criação de "uma nova ciência e tecnologia que seriam fundamentalmente diferentes, que nos colocariam em harmonia com a natureza e não em conflito com ela" (FEENBERG, 2010, p. 214-215).

O equívoco de Max Weber não está tanto em conceber um único tipo de racionalidade como válido, mas em negligenciar a influência dos valores sociais sobre a racionalidade.

A partir desses dois elementos, Feenberg concebe a demanda de Marcuse diferente do que pensava Habermas, como sendo tributária de outra relação com a natureza, a qual não sucumbe aos aspectos românticos e idealistas, mas que se abre para sua constituição enquanto determinada, em certo sentido, pelo contexto social e histórico.

Ainda em relação a Habermas, Feenberg percebe que a mediação entre sistema e mundo da vida tem que admitir, além das categorias dinheiro e poder, também a presença da tecnologia. Isso explicaria as patologias da técnica, especialmente quanto aos seus desvios, como a campanha dos médicos nos anos 40 e 50 pela troca da amamentação materna das crianças pelos produtos da indústria. Para reverter tais equívocos, propõe uma abordagem que garanta a reflexividade da técnica, o que poderia lhe devolver o seu inegável caráter histórico e social. Sendo assim, "As propriedades reflexivas da técnica permitem que ela se volte para si mesma e para seus usuários, como inserida em seu contexto social e natural" (FEENBERG, 2010, p. 236). Nesse aspecto, ele se assemelha aos demais representantes da Escola de Frankfurt, que não admitem a cisão entre valores e fatos no pensamento moderno, evidenciando que C\&T estão moldadas pelas práticas sociais, não como racionalidade pura, mas orientadas num sistema governado pela dinâmica desses valores. O movimento Ciência, Tecnologia e Sociedade procura levar adiante essa tese do ponto de vista da necessidade de redirecionar a sua agenda de desenvolvimento, procurando avançar na crítica social à tecnologia.

\section{A proposta da ciência, tecnologia e sociedade}

A cultura da tecnociência na contemporaneidade coloca-nos um desafio no sentido de se efetuarem análises relacionadas entre a ciência, tecnologia e inovação sob bases não lineares com o intuito de buscar a integração entre 
o técnico e o social, a fim de que as tecnologias atendam os interesses da população. Pode-se dizer, a partir dos Estudos Sociais de Ciência e Tecnologia - ESCT - campo de pesquisa que investiga a relação Ciência, Tecnologia e Sociedade, que são atribuídas duas abordagens para C\&T: a primeira focada apenas em C\&T, enquanto a segunda foca no termo sociedade. Esses estudos incorporam as perspectivas teóricas que indicamos até aqui, notadamente as contribuições oriundas da reflexão filosófica sobre a tecnologia na passagem de Heidegger para Marcuse e Feenberg, acrescida, ainda, dos referenciais de Paulo Freire quando discutidos no campo da educação.

$\mathrm{Na}$ primeira abordagem, C\&T avança inexoravelmente, seguindo um caminho próprio, ou seja, independentemente de qualquer influência social. Essa abordagem percorre uma visão epistemológica positivista, priorizando as chamadas ciências duras e afeitas a uma lógica produtivista. Ela insere-se ainda na denominação de neutralidade da C\&T, ou seja, a ciência não é influenciada pela sociedade. Ainda dentro desse contexto caminha a visão do determinismo tecnológico, corrente que postula a ciência como determinante da técnica, que por sua vez gera o desenvolvimento econômico e este o bem-estar social. $\mathrm{Na}$ perspectiva determinista, o problema não se concentra na matriz do desenvolvimento científico e tecnológico, como questionam Marcuse e Feenberg, mas no uso que se faz da tecnologia.

As políticas científicas e tecnológicas no Brasil e na América Latina são construídas a partir dessa lógica operatória. Suas principais características, segundo Dagnino (2006, p. 43), são: o conhecimento só pode sair da universidade e chegar à sociedade via empresa privada; somente a alta tecnologia irá desenvolver o país; a verdadeira ciência é neutra e universal; a construção de um outro projeto de ciência é heresia. Além disso, podemos dizer que a adoção dessa matriz do conhecimento explica o porquê de algumas áreas se desenvolverem mais do que outras. A biotecnologia, por exemplo, recebeu uma série de apoios de editais e verbas destinadas às pesquisas nos últimos tempos porque, por intermédio do domínio da decodificação do genoma, prometeu revolucionar a produção de fármacos e mesmo da agricultura, com o cultivo dos alimentos transgênicos. O princípio de que a partir da identificação e desativação de um gene causador é possível combater a doença levou a sua aplicação massiva no campo da saúde. Essa lógica simplista e linear ignora que os genes interagem entre si e mesmo como o ambiente em que o organismo está inserido. A biotecnologia sucedera por sua vez o paradigma da física nuclear, da década de 40 e 50 do século passado, em função da guerra fria, e também a física dos transistores, que veio a seguir devido às 
exigências da indústria de miniaturização e robotização dos seus produtos. Porém, justamente essas vinculações explicam que o conhecimento tem uma dependência direta do seu contexto sócio-histórico, respondendo aos valores dos atores hegemônicos.

Além disso, essas políticas são vistas de maneira unidirecional, dentro do paradigma da inovação enquanto transferência de um polo irradiador do conhecimento (seja um país, universidade, empresa, grupo de pesquisa, etc.) para um polo necessitado, neste caso, as populações desassistidas. Um exemplo é o programa Ciências sem Fronteiras, do governo brasileiro, que pretende levar num curto espaço de tempo cerca de 100 mil jovens para estudar nas melhores universidades do mundo. No entanto, a que tipo de ciência e tecnologia terão acesso esses jovens e como se fará essa transferência, sem uma adequação sócio-técnica? Se for realizada de maneira extensiva, isso vai implicar somente um reforço ao neocolonialismo, isto é, a tendência a fazer pesquisa de maneira desligada da nossa realidade sócio-histórica e dos problemas que vivenciamos num país de capitalismo periférico.

Auler e Delizoicov (2006b, p. 2) enfatizam que na década de 60 do século passado, os países do hemisfério norte abriram espaços para participação dos acadêmicos no que tange às temáticas relacionadas a CT. O autor considera que em relação aos países do Norte as ações têm um certo grau de participação devido à razoável satisfação das condições materiais. Entretanto, uma das peculiaridades dos países da América Latina deve-se ao fato de que os mesmos se encontram afetados pela carência material. Outra questão prende-se ao fato que esses países, na sua grande maioria, têm uma estruturação econômica assentada num processo de exploração, cujas marcas, de acordo com o pensamento freiriano, são as da "cultura do silêncio". Essa cultura é responsável pela subserviência aos mecanismos de poder, alijando a participação popular dos processos decisórios da sociedade. Nessa perspectiva, Freire aponta para pressupostos educacionais que transcendem o simples treinamento de competências e habilidades. Pelo contrário, sua obra sinaliza para um projeto utópico implícito ao processo educacional, que aposta na vocação ontológica do homem em "ser mais" - ou seja, ser sujeito histórico e não um mero objeto, e que entende a importância da dimensão ética para construção de uma sociedade mais democrática.

A segunda abordagem, com foco na sociedade, tem como fundamento o fato de que o desenvolvimento da C\&T não é endógeno, mas influenciado pela própria sociedade. Ela nasce a partir da metade do século XX quando graves problemas ambientais começam a ocorrer nos países centrais em decorrência 
da matriz de desenvolvimento científico e tecnológico adotada. A sociedade começa então a questionar e exigir a participação em suas decisões, tendo como foco a preocupação com uma tecnologia de cunho social e não de acordo com os interesses econômicos simplesmente.

O tripé ensino, pesquisa e extensão que dá suporte ao modelo de universidade, nessa perspectiva deveria se iniciar pela extensão, a partir da investigação temática ou de temas geradores, como preconizava Paulo Freire. Dentro dessa abordagem, ciência e tecnologia são socialmente determinadas, classificando-se como tese fraca da neutralidade. Nessa direção não se trata de um rompimento abrupto com a C\&T, como preconiza a tese forte da não-neutralidade, a qual aponta que, devido a sua funcionalidade, ela inibe a mudança social, o que implica uma mudança radical no processo de sua produção. Antes disso é preciso um processo de Adequação Sócio Técnica (AST), buscando uma nova matriz de desenvolvimento para a ciência e a tecnologia, calcada nas peculiaridades locais e regionais da própria sociedade.

No caso latino-americano, isso implicaria pesquisar doenças tropicais aproveitando a biodiversidade dos trópicos, o uso da energia solar e tratamento dos esgotos e efluentes. Seria um tipo de ciência diferente das preocupações dos países do hemisfério norte, porque eles já têm muitos desses problemas superados, ou não dispõem da biodiversidade e da energia solar em abundância, como é o caso latino-americano. Essa perspectiva contraria a tese marxista de que o problema da exclusão das populações dos benefícios do progresso seria resolvido quando os meios de produção, incluindo ciência e tecnologia, fossem socializados. E também a tese pragmatista de que os problemas causados pela ciência e a tecnologia se devem ao seu mau uso, bastando para isso fazer um bom uso dos seus códigos e sistemas operatórios. De outro modo, trata-se de questionar a própria concepção da matriz em que se produz ciência e tecnologia.

\section{Inovação e mudança social}

Dagnino (2005) faz uma crítica ao modelo vigente de inovação na compreensão C\&T, uma vez que o mesmo traz questões relativas ao "produto" conhecimento. $\mathrm{O}$ autor propõe uma perspectiva de interação entre os atores envolvidos, enfatizando a importância de se implementar uma forma distinta relacionada à inovação dentro dos parâmetros da tecnologia social. Para Thomas, tecnologia social é "uma forma de criar, desenvolver, implementar e administrar tecnologia orientada a resolver problemas sociais e ambientais, gerando dinâmicas sociais 
e econômicas de inclusão social e de desenvolvimento sustentável" (2009, p. 27). Esse paradigma caminha na direção de uma tecnologia alternativa, voltada aos valores e objetivos de um cenário de maior equidade. Nesse contexto, os atores sociais interagem desde o seu início na formulação de critérios científicos, técnicos, financeiros, mercadológicos e culturais. Dagnino assim observa:

A contribuição da Teoria da Inovação, ao contrário, nos permite entender que a tecnologia - e especialmente, pelas suas características, a TS - só se constitui enquanto tal quando tiver lugar um processo de inovação, um processo do qual emirja um conhecimento criado para atender os problemas que enfrenta a organização ou grupo de atores envolvidos (2005, p. 5).

Para refletir a respeito da tecnologia social (TS) e sua relação com a proposta de Ciência, Tecnologia e Sociedade, Dagnino, Brandão e Novaes (2004) destacam, no artigo Sobre o marco analítico-conceitual da tecnologia social, a necessidade de uma breve contextualização do surgimento da Tecnologia Social (TS) a partir da ideia de Tecnologia Apropriada (TA). A Índia é considerada o berço do movimento que veio se chamar no Ocidente de TA, tendo por base o pensamento dos reformadores que buscavam o processo de reabilitação das tecnologias tradicionais praticado nas aldeias. Essa situação foi utilizada como estratégia de luta contra o domínio britânico. O processo foi implantado por Gandhi em 1924 e visando a recuperar os processos de fiação manual, tendo a roca de fiar como primeiro equipamento tecnologicamente apropriado. Isso se traduzia numa forma de luta contra a injustiça social e o sistema de castas. Tal processo despertou a consciência política de milhões de hindus, recuperou a indústria, tendo o seguinte lema: "Produção pelas massas, não produção em massa". Essa perspectiva de desenvolvimento tecnológico não se restringia a uma conservação estática das tecnologias tradicionais, mas à adaptação da tecnologia moderna ao meio ambiente, buscando a transformação da sociedade hindu por meio de um crescimento orgânico, de dentro e não implementado de fora. Posteriormente, essas ideias foram aplicadas na República Popular da China, sendo chamada de "tecnologia intermediária". A partir de 1973, com a publicação do livro "Small is beautiful: economics as if people mattered", o conceito de TA é introduzido no mundo ocidental.

Nas décadas de 1970 e 1980 houve um aumento crescente de grupos de pesquisadores partidários da ideia de TA. Nos anos de 1980, com a proliferação no mundo do ideário neoliberal, esse movimento começa a perder seu espaço, face ao cenário político internacional que apoiava uma globalização unipolar que viesse favorecer as grandes economias, penalizando por consequência os países periféricos. 
Porém, o movimento torna a ganhar força a partir de 2005 com a criação no Brasil da Rede de Tecnologia Social (RTS). A proposta sócio-técnica fundamenta a reflexão no sentido de que as dimensões sociais, psicológicas, ambientais e tecnológicas devem ser avaliadas como um todo. Elas devem ser tratadas numa perspectiva de totalidade, colocando um desafio ao foco tradicional tecnocêntrico de trabalho, assumindo a defesa de que elementos socais e técnicos formam um sistema e devem ser considerados conjuntamente.

Essas abordagens conduzem a caminhos que levam ao debate em relação à concepção da Ciência e Tecnologia, propondo questionamento sobre os seus efeitos e respectivos benefícios, portanto. Tudo isso leva a crer que a questão de fundo, segundo Dagnino (2008), para os que advogam em favor da neutralidade da C\&T, não é a tecnologia, mas as tecnologias e as opções em termos de trilhas do progresso a serem percorridas. Essa postura se embasa na concepção de uma ciência pura e que contrasta com os valores de outra esfera que explicita preferências subjetivas. Se assim for, as opções em termos de C\&T implicam uma distribuição desigual de poder entre os atores sociais, de uso da influência sobre o processo de concepção de tecnologia que pode contribuir para a injustiça.

Diante de tal contexto, a alternativa da tecnologia e inovação social se preocupa em como a ciência pode humanizar o ser humano, ou seja, propõe que a mesma não esteja unicamente pautada pelo seu valor epistêmico ou mercadológico, mas possa contribuir para a justiça social e o bem-estar do cidadão, como pano de fundo normativo da transformação social. Essa preocupação com o bem-estar tem por base uma teoria de mudança social democrática, que permite refletir sobre o processo de decisão das alternativas tecnológicas que precisam ser encaminhadas para além dos interesses do capital, ou melhor, precisam encontrar-se inseridas dentro de um modo de conceber as tecnologias em estreita relação com os aspectos sociais. Essa lógica prevê a comunicação e a intercomunicação entre os atores sociais envolvidos e a valorização do saber local que se inter-relaciona ao saber científico, e não a sua simples extensão ou transferência, como se alguém pudesse levar a outro a inovação do conhecimento pretendido. Refletir inovação nessa perspectiva envolve como ponto de partida a "leitura crítica da realidade", ou seja, a compreensão crítica sobre interações entre CTS. Nesse processo é importante, além da superação da "cultura do silêncio", que leva à subserviência ao modelo de decisões tecnocráticas, também a meta de democratização das decisões em temas envolvendo CT. 


\section{Considerações finais}

O Brasil vivencia na atualidade um projeto de disputa política, econômica e cultural. O grande desafio é a inserção de um número cada vez maior de pessoas para escrever esse projeto, a fim de, na perspectiva do equacionamento com a democracia, decidir que filosofia da tecnologia é importante associar ao projeto de desenvolvimento nacional. Como vimos até o presente, as opções nesse sentido vão desde a crítica política, conforme proposto por Chaui, transitando para a crítica cultural, de acordo com os preceitos frankfurtianos de Marcuse e Feenberg, até chegar a uma crítica social própria do movimento Ciência, Tecnologia e Sociedade. Essas propostas contribuem para alavancar o debate sobre os "avanços" da modernidade de uma crítica conservadora da tradição, conforme é pressuposto na herança heideggeriana, em direção a um patamar de maior preocupação com a inovação social.

Como procuramos mostrar até aqui, o trabalho questiona o otimismo revolucionário prometeico da técnica, o qual tem levado a certo esquecimento de outras formas de compreender a relação que podemos estabelecer com ela. Além disso, sugere a necessidade da intensificação do enfrentamento dessa questão sob o ponto de vista dos avanços da discussão no campo da filosofia da tecnologia, e também da educação, uma vez que, caso permanecermos na inércia frente a esse problema, acabaremos contribuindo para que prolifere certo cinismo tecno-pedagógico. Trata-se de questionar as bases metafísicas do pensar tecnológico, bem como a necessidade de uma reconfiguração antropológica face ao bombardeio sensorial produzido pelas novas tecnologias, as quais produzem apenas novos modos de ser e não um novo conceito de cidadania que se constitui pela via das tecnologias.

Sendo assim o conservadorismo que advém da linha de reflexão de Heidegger - de que a técnica, na modernidade, adquire caráter instrumental e antropológico, e que perpassa a obra de Gadamer e Hannah Arendt, foi também assumido pelos pioneiros da Escola de Frankfurt (Adorno e Horkheimer) e mais tardiamente por Habermas. Essa espécie de "essencialização" da técnica pode significar retrocessos em relação aos avanços políticos já conquistados na discussão a respeito do assunto, por isso optamos por refletir sobre esse tema a partir de uma produção já consolidada - a dos Estudos Sociais de Ciência e Tecnologia - ESCT.

Construir tecnologias sociais para um efetivo desenvolvimento deve fazer parte da agenda da tecnociência, bem como do processo de democratização do país. As grandes empresas conseguem criar estruturas próprias de apro- 
priação das inovações tecnológicas, enquanto o circuito inferior da economia, composto por pequenas e médias empresas, organizações comunitárias, sociedade civil, universidades e outras instituições formativas carecem de um sistema articulado nesse sentido. $\mathrm{O}$ "andar de cima" potencializa a acumulação pela revolução vigiada da tecnologia da informação e pela possibilidade de fragmentação das cadeias produtivas globais. Por isso as políticas públicas e os instrumentos de construção dos sistemas socioténicos devem estar em consonância com as relações sociais, ou seja, é necessário que privilegiem questões políticas, econômicas, de gênero e raça que são peculiares do nosso país. Para se discutir o desenvolvimento social, é preciso colocar em pauta a transição dos microprocessos de inclusão social para macroprocessos baseados nos mesmos princípios, ou seja, devem ser orientados por políticas pautadas pela tecnologia e inovação compreendidas numa visada social.

O país necessita de ações concretas no sentido de avançar para além da concepção de neutralidade e do determinismo tecnológico em termo de CTS, em direção a uma biopolítica emancipatória. Observa-se concretamente que muitos debates que presenciamos a respeito de tais questões não ultrapassam uma visão engessada à manutenção do status quo, pois não chegam a um questionamento das racionalidades matriciais geradoras das situações extremas vivenciadas pela humanidade na contemporaneidade, gerando, no universo das instituições educacionais, a formação de verdadeiros analfabetos científicos. Acreditamos que ações podem ser desenvolvidas em articulação com perspectivas que levem em consideração alguns marcos teóricos expostos até aqui.

Primeiramente, há que se levar em conta que a leitura da palavra e a leitura do mundo devem ser consideradas numa perspectiva dialética. A CT deve admitir que um dos pressupostos de inclusão começa com a alfabetização científica, que consiste no "aprender a dizer a palavra", ou seja dar voz e vez aos oprimidos na perspectiva emancipatória. Concebe-se que, segundo Auler e Bazzo (2001) e Auler e Delizoicov (2006a, 2006b) para uma leitura crítica da realidade torna-se fundamental uma compreensão sobre as interações CTS, considerando que a dinâmica social na contemporaneidade encontra-se intimamente relacionada ao desenvolvimento científico-tecnológico. Portanto, a leitura crítica do mundo contemporâneo passa por ações voltadas à superação da lógica vigente, mantenedora do status quo, para um tipo de abordagem inovadora, que aposta na ideia de tecnologia e inovação social.

Considera-se fundamental a utilização da categoria "problematização" a construções históricas pouco consistentes em termos científico-tecnológicos. Segundo Auler e Delizoicov (2006a, p. 338), trata-se da superação do modelo 
de decisões tecnocráticas que por sua vez busca a eliminação do sujeito do processo científico-tecnológico; superação da perspectiva salvacionista e redentora atribuída à ciência e tecnologia, bastante difundida no sentido de que CT resolverão todas as demandas, conduzindo à humanidade ao bem-estar social, ignorando por sua vez as relações sociais em que CT são concebidas e utilizadas; superação do determinismo tecnológico que advoga a concepção de que a mudança tecnológica é causa da mudança social e que a tecnologia é autônoma e independente das influências sociais.

Essa análise do desenvolvimento científico-tecnológico aproxima a discussão dos argumentos em prol da não neutralidade da educação, ou seja, de um processo neutro de alienação do sujeito. Esse posicionamento leva a uma sintonia com a CTS no sentido de valorização da sociedade na participação das decisões democráticas, em detrimento das decisões tecnocráticas, a partir da reversão do que Freire denominou "cultura do silêncio", uma vez que ontologicamente a vocação do homem é ser mais, ou seja, ser humano como sujeito histórico e não como objeto.

Nesse contexto a inovação é compreendida como coparticipação dos agentes implicados, atuando como protagonistas de um processo de reconstrução social que decide conjuntamente sobre a pertinência ou não de adotar soluções a partir de critérios próprios. Por isso, partindo do pressuposto de que a sociedade deve participar dos processos decisórios numa perspectiva de democratização, e de que a dinâmica social contemporânea deve estar atenta aos rumos do desenvolvimento científico e tecnológico, é urgente repensar o envolvimento da sociedade nessas questões. A universidade, por exemplo, não teria mais o que "estender", mas ela auxiliaria a identificar problemas, começando pelos temas locais, trabalhando no paradigma da inovação social. Os próprios currículos seriam definidos segundo critérios de problematização da realidade e não de forma disciplinar, mas por eixos temáticos compostos de maneira inter ou transdisciplinar por demandas sensíveis à realidade sócio-histórica.

Afinal, os problemas não se reduzem ao campo científico, mas carregam valores e aspectos sociais, éticos e culturais, o que exige uma educação em ciência e tecnologia, uma verdadeira alfabetização científica. Certamente a intuição pioneira de Marcuse estaria aqui, de certa maneira, contemplada, vez que a tecnologia e a ciência iriam contribuir para a construção de relações miméticas ou fraternais do homem com o seu entorno, dado que o ser humano não competiria mais com a natureza, mas tornar-se-ia efetivamente seu parceiro. 


\section{Referências}

AULER, Décio; BAZZO, Walter Antonio. Reflexões para a implementação do movimento CTS no contexto educacional brasileiro. Ciência \& Educação, Bauru, v. 7, n. 1, p. 1-13, 2001.

AULER, Décio; DELIZOICOV, Demétrio. Ciência-Tecnologia-Sociedade: relações estabelecidas por professores de ciências. Revista Electrónica de Enseñanza de las Ciencias, Vigo, v. 5, n. 2, p. 337-355, 2006a.

. Educação CTS: Articulação entre pressupostos do educador Paulo Freire e referenciais ligados ao movimento CTS. In: LÓPES, A. B.; PEINADO, V-B.; LÓPES, M. J.; RUZ, M. T. P. (Org.). Las relaciones CTS en la Educación Científica. Málaga: Editora da Universidade de Málaga, 2006b. v. Único, p. 1-7.

BRASIL. MINISTÉRIO DA CIÊNCIA, TECNOLOGIA E INOVAÇÃO. Estratégia Nacional de Ciência, Tecnologia e Inovação 2012 - 2015. Balanço das atividades estruturantes 2011. MCTI, Brasília: DF, 2012.

CHAUI, Marilena. Convite à filosofia. 6. ed. São Paulo: Ática, 1997.

DAGNIGNO, Renato. A adequação sócio-técnica na agenda do complexo de C\&T e dos empreendimentos autogestionários. In: SEMINÁRIO LATINOIBEROAMERICANO DE GESTIÓN TECNOLÓGICA, 11. 2005, Salvador, BA. [Anais...]. Salvador/BA: ALTEC, 2005. p. 1-13.

DAGNIGNO, Renato. Ciência e tecnologia para o desenvolvimento local: uma proposta transformadora. RDE - Revista de Desenvolvimento Econômico, Salvador, v. 8, n. 14, p. 43-52, 2006.

DAGNIGNO, Renato. Neutralidade da ciência e determinismo tecnológico: um debate sobre a tecnociência. Campinas, SP: Ed. da UNICAMP, 2008.

DAGNIGNO, Renato. Prefácio. In: NEDER, Ricardo T. (Org.). A teoria crítica de Andrew Feenberg: racionalização democrática, poder e tecnologia. Brasília. Observatório do Movimento pela Tecnologia Social na América Latina / CDS / UnB / Capes, 2010. Disponível em: https://www.sfu. ca/ andrewf/ coletanea.pdf. Acesso em: 31 ago. 2013. 
DAGNINO, Renato; BRANDÃO, Flávio Cruvinel; NOVAES, Henrique Tahan. Sobre o marco analítico-conceitual da tecnologia social. In:

TECNOLOGIA social: uma estratégia para o desenvolvimento. Rio de Janeiro: Fundação Banco do Brasil, 2004. p. 15-64. Disponível em: http:// gife.issuelab.org/resource/tecnologia_social_uma_estrategia_para_o_ desenvolvimento. Acesso em: 31 ago. 2013.

FEENBERG, Andrew. Marcuse ou Habermas: duas críticas da tecnologia. In: NEDER, Ricardo T. A teoria crítica de Andrew Feenberg: racionalização democrática, poder e tecnologia. Brasília. Observatório do Movimento pela Tecnologia Social na América Latina / CDS / UnB / Capes, 2010. Disponível em: https://www.sfu.ca/ andrewf/ coletanea.pdf. Acesso em: 31 ago. 2013.

MARCUSE, Herbert. Tecnologia, guerra e fascismo. São Paulo: Fundação Editora da UNESP, 1999.

NEDER, Ricardo T. (Org.). A teoria crítica de Andrew Feenberg: racionalização democrática, poder e tecnologia. Brasília: Observatório do Movimento de Tecnologia Social na América Latina/ CDS/UnB/ Capes, 2010 .

THOMAS, Hernán Eduardo. Tecnologias para inclusão social e políticas públicas na América Latina. In: OTTERLOO, Aldalice et al. Tecnologias sociais: caminhos para a sustentabilidade. Brasília: DF, 2009. p. 25-71.

Geraldo Antônio da Rosa - Universidade de Caxias do Sul Caxias do Sul | RS | Brasil. Contato: garosa6@ucs.br

Amarildo Luiz Trevisan - Universidade Federal de Santa Maria Santa Maria | RS | Brasil. Contato: trevisanamarildo@gmail.com 
